\title{
IL6 genotype, tumour ER-status, and treatment predicted disease-free survival in a prospective breast cancer cohort
}

\author{
Andrea Markkula', Maria Simonsson ${ }^{1}$, Christian Ingvar ${ }^{2}$, Carsten Rose ${ }^{3}$ and Helena Jernström ${ }^{1 *}$
}

\begin{abstract}
Background: In breast cancer, high levels of the inflammatory cytokine interleukin-6 (IL-6) have been associated with disease-free survival and treatment resistance. Increased serum levels of IL-6 have been correlated with increased levels of NF-k $\beta$ and aromatase expression in adipose tissue. Several IL6 single nucleotide polymorphisms have been associated with breast cancer prognosis, but the impact may differ depending on tumour oestrogen receptor (ER) status. This translational study investigated the association between IL6 genotypes, ER-status, and treatment on the risk of early events among breast cancer patients.

Methods: The study included 634 25- to 99-year-old primary breast cancer patients in Sweden from 2002-2008. Genotyped IL6 single nucleotide polymorphisms rs1800797, rs1800796, rs1800795, and rs2069849 were analysed separately and as diplotypes. Disease-free survival was assessed for 567 patients. Clinical data, patient-, and tumour-characteristics were obtained from questionnaires, patient charts, population registries, and pathology reports.

Results: The median follow-up time was 5.1 years. IL6 diplotype was not associated with early events for all 567 patients, but AGCC/AGCC diplotype-carriers with ER-negative tumours had an increased risk, (adjusted Hazard Ratio $(H R)=5.91,95 \% \mathrm{Cl}: 1.28-27.42$ ). Any C-carriers (rs 1800795) with ER-negative tumours had a higher risk of early events than GG-carriers with ER-negative tumours, (adjusted HR=3.76, 95\% Cl: 1.05-13.43), particularly after radiotherapy (adjusted HR=7.17, 95\% Cl: 1.16-32.28). Irrespective of ER-status, chemotherapy-treated Any C-carriers had a higher risk of early events than GG-carriers (adjusted HR $=3.42,95 \%$ Cl: $1.01-11.54$ ).

Conclusions: The main finding of the present study was that IL6 genotype was strongly associated with early events among patients with ER-negative tumours, particularly among radiotherapy-treated patients, and among chemotherapy-treated patients irrespective of ER-status. The high risk for early events observed in these subgroups of patients suggests that combined information on IL6 genotype, tumour ER-status, and breast cancer treatment may represent a tool for identifying patients who require more personalised treatment.
\end{abstract}

Keywords: Breast cancer, IL6, Oestrogen receptor, Chemotherapy, Radiotherapy, Treatment resistance

\section{Background}

Breast cancer is the most prevalent type of cancer among women and the primary cause of cancer death among women worldwide [1]. Breast cancer treatment resistance is common and increases mortality [2]. Novel prognostic and treatment-predictive markers may lead to more personalised breast cancer treatment and improved prognosis.

\footnotetext{
* Correspondence: helena.jernstrom@med.lu.se

'Division of Oncology and Pathology, Department of Clinical Sciences, Lund, Lund University, Barngatan 2B, Lund SE-22185, Sweden

Full list of author information is available at the end of the article
}

In breast cancer patients, a high level of the inflammatory cytokine interleukin-6 (IL-6) has been associated with increased tumour stage, lymph node infiltration, recurrence, and treatment resistance [3-5]. Increased serum levels of IL-6 has been correlated with increased levels of NF- $k \beta$, which may represent a mechanism for tumour resistance to chemotherapy and radiotherapy [6]. Further, IL-6 has been shown to stimulate aromatase expression in adipose tissue; aromatase expression subsequently stimulates oestrogen synthesis, potentially contributing to breast cancer progression [7]. 
Several IL6 single nucleotide polymorphisms (SNPs) have been associated with breast cancer risk and prognosis. An IL6 haplotype that consists of the SNPs rs1800797 $(-596 \mathrm{~A}>\mathrm{G}), \operatorname{rs} 1800796(-572 \mathrm{G}>\mathrm{C}),-373[10 \mathrm{~A} / 11 \mathrm{~T}]$, and rs1800795 $(-174 \mathrm{G}>\mathrm{C})$ was associated with reduced disease-free survival among breast cancer patients [8]. In a previous study, postmenopausal women with the SNP rs1800797 AA genotype had an increased risk of breast cancer, even if they had not recently been exposed to hormones [9]. Further, patients with oestrogen receptor (ER)positive tumours and the SNP rs1800797 GG genotype had reduced disease-free survival compared to patients with the CC or GC genotypes [8].

The well-studied SNP rs1800795/-174 G > C that is located in the promoter region of IL6 has been associated with fatigue and survival among breast cancer patients $[8,10-12]$, and the effects of this SNP appear to vary according to tumour ER-status $[8,10]$. The relationship between genotype and plasma levels of IL-6 appears to be complex. The $-174 \mathrm{C}$-allele has been associated with increased IL- 6 and C-reactive protein (CRP) levels, particularly in inflammatory conditions [13-15]; however, conflicting results have been reported [16,17].

High levels of circulating IL-6 are associated with fatigue and depression among breast cancer patients [6], and depression is associated with reduced breast cancer survival [18]. Antidepressant treatment reduced IL-6 levels in depressed patients [19] and increased adherence to adjuvant breast cancer treatment [20]. In addition, antidepressant treatment has been hypothesised to increase survival among depressed cancer patients [21].

To identify novel breast cancer markers of possible prognostic or treatment-predictive importance among breast cancer patients, investigations of the combined effects of antidepressant use, breast cancer treatment, ER-status, and IL6 genotype on breast cancer prognosis are necessary. We hypothesised that IL6 genotype can affect the risk of early events and treatment response and that the impact of this genotype is further modified by ER-status. Hence, the aim of this study was to investigate the impact of the IL6 SNPs rs1800797, rs1800796, rs1800795, rs2069849 and IL6 diplotypes based on these SNPs in relation to tumour ER-status on early events and treatment response.

\section{Methods}

\section{Study population}

Beginning in October 2002, women who were diagnosed with a first breast cancer at the Skåne University Hospital in Lund, Sweden were invited preoperatively to participate in the ongoing prospective BC-blood study. The Skane University Hospital in Lund serves nearly 300,000 inhabitants. Since patients are not referred to other hospitals for surgery, the cohort is considered population-based.
During the time the cohort was compiled, 1,090 patients received breast cancer surgery at the hospital. Approximately $58 \%$ of these patients were included in the study. Patients were missed primarily due to a lack of available research nurses. The included patients were similar to the non-included patients with respect to age and hormone receptor status [22]. Patients with a prior history of breast cancer or another cancer diagnosis within the previous ten years were excluded. The majority of the patients who were diagnosed in Lund were ethnic Swedes; however, ethnicity information was not obtained during this study.

This paper presents data collected from 634 patients who initiated treatment between October 2002 and October 2008. Treatment was administered according to the standard of care at Skane University Hospital. The patients were asked to complete questionnaires prior to surgery, three to six months after surgery and one, two, three, five, seven, and nine years after surgery. The followup rates in the present cohort were high [23]. Written informed consent was obtained from all patients, and the study was approved by the Lund University ethics committee (Dnr 75-02, 37-08, and 658-09).

During the preoperative visit, blood samples were collected for genotyping. The research nurses also measured body weight, height, and waist and hip circumferences during the preoperative visit. The volume of each breast was measured using plastic cups, as previously described [24]. The waist circumference was measured at the umbilicus; the hip circumference was measured at the widest part between the hip and trochanter major. The questionnaire included questions regarding the date of surgery, reproductive history, exogenous hormone use, smoking history (i.e., yes/no/occasional smoker) and alcohol consumption. Patients who identified themselves as regular smokers and occasional smokers during the preoperative visit or at any subsequent visit were classified as smokers. A body mass index (BMI) cut-off value of $25 \mathrm{~kg} / \mathrm{m}^{2}$ was used, according to the WHO's classification of overweight [25]. Central obesity was considered to be present if the waist-to-hip ratio (WHR) was above 0.85 [25]. Questions regarding alcohol consumption frequency were based on the alcohol use disorders identification test (AUDIT) [26]. A breast volume cut-off of $850 \mathrm{ml}$ was chosen based on a previous publication [27]. Mammography-detected tumours in patients aged 45-74 years at the time of diagnosis were considered to be screening-detected. Patients within this age category were invited to mammography screening in Sweden during the study inclusion period. Antidepressant use was coded as a dummy variable based on the information obtained from the preoperative questionnaire [28].

Information regarding the type of adjuvant treatment, sentinel node biopsy results, axillary lymph node dissection and type of surgery was collected from patient charts. 
Treatment information was also collected from questionnaires and was recorded up to the time of the last follow-up appointment or death, prior to any event. Data on invasive tumour size, histological type and grade, and number of involved axillary lymph nodes were obtained from each patient's pathology report. ER and progesterone receptor (PgR) status were determined as previously described $[29,30]$.

The tumours were analysed in the Department of Pathology at Skåne University Hospital in Lund. Information concerning breast cancer events, including local or regional recurrence, new breast cancer, or distant metastases, was obtained from patient charts, pathology reports and the Regional Tumour Registry. The date of death was obtained from the Swedish Population Registry.

\section{Genotyping}

Genomic deoxyribonucleic acid (DNA) was extracted from the leukocyte portion of whole blood using a Wizard Genomic DNA Purification Kit (Promega, Madison, WI, USA). Genotyping was performed at the Region Skane Competence Centre (RSKC Malmö) of Malmö University Hospital in Malmö, Sweden. The SNPs rs1800797, rs1800796, rs1800795, and rs2069849 were analysed via matrix-assisted laser desorption/ionisation time-of-flight mass spectrometry using a Sequenom MassARRAY ${ }^{\oplus}$ platform (Sequenom, San Diego, CA, USA) and iPLEX reagents, according to the manufacturers' protocol. Sequenom MassARRAY ${ }^{\circledR}$ software (Sequenom) was used for multiplex SNP analysis design. Over $10 \%$ of the samples were run in duplicate, with a concordance of $100 \%$.

\section{IL6 diplotype construction}

Each SNP was cross-tabulated against the other three SNPs. This procedure demonstrated that certain combinations did not exist or were very rare. Therefore, we constructed the haplotypes and diplotypes based on the most likely combinations. The IL6 diplotype consisted of four IL6 SNPs: rs1800797 $(-596 \mathrm{~A}>\mathrm{G})$, rs1800796 $(-572 \mathrm{G}>\mathrm{C} /-634 \mathrm{C}>\mathrm{G}), \quad \mathrm{rs} 1800795 \quad(-174 \mathrm{G} / \mathrm{C})$, and rs2069849 (C/T coding exon 5). Diplotype variants that were present in less than $5 \%$ of the patients were classified as rare variants and combined into a single group termed 'rare diplotypes.' IL6 diplotype information was missing for nine patients. Rs1800797 analysis failed for five patients; of these cases, three SNPs could be imputed based on rs1800795, as the $\mathrm{R}^{2}$ between these two SNPs was 0.966. Consequently, while rs1800795 analysis failed for four patients, two SNPs could be imputed based on rs1800797. The two remaining SNPs lacked information related to both Rs1800797 and Rs1800795 and could therefore not be imputed. Rs1800796 analysis failed for seven patients.

\section{Data analyses}

Statistical analyses were performed using IBM SPSS Statistics 19.0 (Chicago, IL, USA). Each patient's BMI was calculated by dividing weight in kilograms by the square of patient height in meters $(\mathrm{kg} / \mathrm{m} 2)$. The WHR was calculated as waist circumference divided by hip circumference.

IL6 genotype was analysed in relation to tumour and patient characteristics. IL6 gentype was analysed in relation to patient characteristics (i.e., age at diagnosis, weight, height, BMI, WHR, age at menarche, and total breast volume) using the non-parametric Kruskal-Wallis test because these variables were continuous and not normally distributed. Chi-square analyses were used to investigate the relationship between IL6 genotype and the categorical variables breast volume $\geq 850 \mathrm{ml}$ (yes/no), parous (yes/no), preoperative use of antidepressants (yes/no), any hormone replacement therapy use (HRT) (yes/no), preoperative smoking (yes/no), smoking at any visit (yes/no), alcohol consumption frequency, screeningdetected tumour (yes/no), invasive tumour size (in situ, $\leq 20 \mathrm{~mm}, 21-50 \mathrm{~mm}, \geq 51 \mathrm{~mm}$, skin or muscle involvement, or $21 \mathrm{~mm}$ or larger), histological grade (I-III or III), axillary lymph node involvement $(0,1-3,4+$, or any axillary lymph node involvement (yes/no)), ER-status (positive/negative), PgR status (positive/negative), and the combination variables ER- and PgR-positive (yes/no), ERand PgR-negative (yes/no), ER-positive and PgR-negative (yes/no), and ER-negative and PgR-positive (yes/no).

To analyse breast cancer-free survival, patients were followed from inclusion to the first breast cancer event. Patients without events were followed until the last follow-up or death prior to January 1, 2013. Of 634 patients, 567 were included in the survival analyses of IL6 diplotype and 574 patients were included in the survival analyses of rs1800795.

For the univariable survival analysis, the Log-Rank test was used to analyse the risk of early cancer events in relation to IL6 genotype, ER-status, and breast cancer treatment. Due to the small number of homozygous rs1800795 minor allele carriers, the $\mathrm{G} / \mathrm{C}$ and $\mathrm{C} / \mathrm{C}$ genotypes were combined into a single "Any $C$ " genotype for the survival analyses. For the multivariable analysis, Cox regression was used to calculate Hazard Ratios (HRs) in relation to rs1800795, adjusting for age (linear), invasive tumour size ( $\geq 21 \mathrm{~mm}$ or muscular or skin involvement), axillary lymph node involvement (yes/no), and histological grade III (yes/no). Since few patients exhibited an invasive tumour size $\geq 51 \mathrm{~mm}$ or muscular or skin involvement, these patients were combined with the patients with invasive tumour sizes between 21 and $50 \mathrm{~mm}$ in the multivariable analyses. In the multivariable analyses of rs1800795, a categorical variable that combined rs1800795 and ER-status was used. Adjustments were made using breast volume, 
BMI, and WHR as either dichotomous or continuous variables. Breast volume was not normally distributed and was therefore transformed using the natural logarithm (ln). Prior power calculations that assumed 600 patients with an accrual interval of 6 years, an additional follow-up time of 2 years and 30\% of patients with a variant allele demonstrated that the study was able to detect true HRs between 0.722 and 1.440 with $80 \%$ power and an $\alpha$ of 5\% [31]. Further, simulations with $80 \%$ failure rates were also performed, demonstrating that the study had sufficient power to detect an increased HR of 1.9 with a genotype frequency of $30 \%$.

A $P$-value $<0.05$ was considered significant. All $P$-values were two-tailed. Since this was an exploratory study, nominal $P$-values are presented without adjustments for multiple testing. The report is based on the REMARK criteria [32].

\section{Results}

IL6 htSNP analyses were performed for 634 patients. Genotype information was missing for nine women. Five different haplotypes and 11 different diplotypes were identified in the cohort. The two most common haplotypes were AGCC (45.3\% of patients) and GGGC (46.6\% of patients). The three most common diplotypes were AGCC/ GGGC, AGCC/AGCC, and GGGC/GGGC (38.2, 23.2, and $23.5 \%$ of patients, respectively). The eight diplotype variants that were present in less than $5 \%$ of the patients were classified as rare variants and combined into a single group termed 'rare diplotypes'.

\section{Patient and tumour characteristics}

Patient characteristics for the 567 patients with diplotype information and the 574 patients with information on rs1800795 genotype who were included in the survival analyses are presented in Table 1. Tumour characteristics for the 567 patients with diplotype information and the 574 patients with information on rs1800795 genotype who were included in the survival analyses are presented in Table 2. Patient characteristics for all 634 patients, for the 567 patients with diplotype information, and the 574 patients with information on rs1800795 genotype who were included in the survival analyses are presented in Additional file 1. Tumour characteristics for all patients included the 592 patients who had not received preoperative treatment, for the 567 patients included in the diplotype survival analyses, and for the 574 patients included in the rs1800795 survival analyses are presented in Additional file 2. A borderline significant association was observed between carrying the AGCC/ GGGC diplotype and having a non-screening-detected tumour $(P=0.063)$. The GGGC/GGGC diplotype was borderline significantly associated with ER and PgR negativity $(P=0.055)$. For rs1800795, GC-carriers had a borderline significant increased risk of an invasive tumour size $\geq 21 \mathrm{~mm}(P=0.061)$.

\section{Early events in relation to IL6 diplotype}

Patients who had received preoperative treatment $(n=42)$, who were diagnosed with carcinoma in situ $(n=14)$, and/ or who had metastases detected earlier than three months after study inclusion $(n=2)$ were excluded from the survival analyses. A flowchart of the patients included and excluded in the analyses is presented in Figure 1. Among the 567 remaining patients, 86 were diagnosed with some type of breast cancer event (i.e., ipsi/contralateral, regional, or distant metastasis) during the 9-year follow-up time period; 54 of these patients had distant metastases. The median follow-up time was 5.1 years (IQR 3.0-7.1 years).

Among these 567 patients, IL6 diplotype was not associated with early events in a univariable model (Figure 2a; Log Rank 3 df; $P=0.83$ ) or in a multivariable model when adjusting for tumour size, axillary lymph node involvement, age, and histological grade III (adjusted $\mathrm{HR}=1.14$; 95\% CI 0.62-2.10; $P=0.67)$. The addition of ER-status, BMI, WHR or breast volume to the model did not significantly change the results.

\section{Early events in relation to IL6 diplotype and ER-status}

Among the 73 patients with ER-negative tumours, patients with the AGCC/AGCC or AGCC/GGGC genotypes had an increased risk of early events (Figure 2b; Log Rank $3 \mathrm{df} ; P=0.014$ ). In a multivariable model, this difference was only significant for the AGCC/AGCC diplotype (adjusted $\mathrm{HR}=5.91 ; 95 \%$ CI 1.28-27.42; $P=0.023$ ) compared to the GGGC/GGGC diplotype. When the dichotomous variable breast volume $\geq 850 \mathrm{ml}$ was added to the model, the association between IL6 AGCC/AGCC diplotype and risk of early events was strengthened (adjusted $\mathrm{HR}=7.29$; 95\% CI 1.54-34.53; $P=0.012$ ). The results remained essentially the same when BMI or WHR was added to the model.

Among the 492 patients with ER-positive tumours, the IL6 diplotype was not associated with the risk of early events in a univariable model ( $\log$ Rank $3 \mathrm{df} ; P=0.50)$ or in a multivariable model (adjusted $\mathrm{HR}=0.73 ; 95 \% \mathrm{CI}$ $0.37-1.45 ; P=0.36$ ). The addition of body constitution to the model did not essentially change the results.

\section{Early events in relation to IL6 diplotype, ER-status, and breast cancer treatment}

Chemotherapy-treated patients with ER-negative tumours who had either an AGCC/GGGC or an AGCC/AGCC diplotype had an increased risk of early events (Log Rank $3 \mathrm{df} ; P=0.031$ ). This association was not observed among chemotherapy-treated patients with ER-positive tumours (Log Rank 3 df; $P=0.95$ ). In a multivariable model of patients with ER-negative tumours who had received 
Table 1 Patients included in the survival analyses stratified according to IL6 diplotype (A) and rs1800795 (B)

\begin{tabular}{|c|c|c|c|c|c|c|c|c|c|c|c|}
\hline & \multicolumn{6}{|c|}{ (A) } & \multicolumn{5}{|c|}{ (B) } \\
\hline & \multirow{2}{*}{\multicolumn{2}{|c|}{$\begin{array}{l}\text { Patients included } \\
\text { in the diplotype } \\
\text { survival analyses }\end{array}$}} & \multicolumn{4}{|c|}{ Stratified according to IL6 diplotype* } & \multirow{2}{*}{$\begin{array}{l}\text { Patients included } \\
\text { in the rs1800795 } \\
\text { survival analyses }\end{array}$} & \multicolumn{4}{|c|}{ Stratified accoding to rs $1800795^{* *}$} \\
\hline & & & GGGC/GGGC & AGCC/GGGC & AGCC/AGCC & $\begin{array}{c}\text { Rare } \\
\text { diplotypes }\end{array}$ & & & GG & GC & CC \\
\hline & $\begin{array}{l}\text { Median }\left(\mathrm{IQR}^{* * *}\right) \\
\quad \text { or } \mathrm{n}(\%)\end{array}$ & Missing & $\begin{array}{l}\text { Median (IQR) } \\
\text { or } n(\%)\end{array}$ & $\begin{array}{l}\text { Median (IQR) } \\
\text { or } n(\%)\end{array}$ & $\begin{array}{l}\text { Median (IQR) } \\
\text { or } n(\%)\end{array}$ & $\begin{array}{l}\text { Median (IQR) } \\
\text { or } \mathrm{n}(\%)\end{array}$ & $\begin{array}{l}\text { Median }\left(\mathrm{IQR}^{* * *}\right) \\
\text { or } n(\%)\end{array}$ & Missing & $\begin{array}{l}\text { Median (IQR) } \\
\text { or } n(\%)\end{array}$ & $\begin{array}{l}\text { Median (IQR) } \\
\quad \text { or } n(\%)\end{array}$ & $\begin{array}{c}\text { Median (IQR) } \\
\text { or } n(\%)\end{array}$ \\
\hline$n=$ & 567 & & $130(22.9)$ & $221(39.0)$ & $131(23.1)$ & $85(15.0)$ & 574 & & $181(31.5)$ & $257(44.8)$ & $136(23.7)$ \\
\hline $\begin{array}{c}\text { Age at diagnosis, } \\
\text { yrs }\end{array}$ & $59.7(51.8-66.3)$ & - & $60.5(49.2-66.7)$ & $59.5(51.4-66.7)$ & $59.8(53.8-66.4)$ & $58.4(51.1-65.2)$ & $59.8(52.0-66.4)$ & - & $60.5(49.9-67.1)$ & $59.5(52.2-66.4)$ & $59.8(53.8-66.3)$ \\
\hline Weight, kgs & $68.0(61.0-76.7)$ & 2 & $69.0(62.0-81.3)$ & $67.0(60.0-75.0)$ & $68.0(61.0-78.5)$ & $68.3(62.0-77.6)$ & $68.0(61.0-76.9)$ & 2 & $69.0(61.9-80.0)$ & $67.1(60.4-75.0)$ & $69.0(61.0-78.9)$ \\
\hline Height, m & $1.66(1.62-1.70)$ & 1 & $1.66(1.62-1.71)$ & $1.65(1.62-1.69)$ & $1.65(1.62-1.70)$ & $1.67(1.60-1.70)$ & $1.66(1.62-1.70)$ & 1 & $1.66(1.60-1.71)$ & $1.66(1.62-1.69)$ & $1.66(1.62-1.70)$ \\
\hline $\mathrm{BMI}, \mathrm{kgs} / \mathrm{m}^{2}$ & $24.6(22.3-27.7)$ & 3 & $25.2(22.9-29.1)$ & $24.3(21.9-26.9)$ & $24.6(22.4-28.6)$ & $24.4(22.2-28.2)$ & $24.6(22.3-27.9)$ & 3 & $25.2(22.6-28.7)$ & $24.4(22.1-27.4)$ & $24.6(22.4-28.8)$ \\
\hline Breast volume & $1000(600-1450)$ & $75^{\mathrm{a}}$ & 1000 (700-1538) & $950(600-1450)$ & $988(600-1450)$ & $900(585-1563)$ & $1000(600-1450)$ & $75^{\mathrm{a}}$ & $950(650-1400)$ & $1000(625-1563)$ & 1000 (600-1450) \\
\hline $\begin{array}{l}\text { Breast volume } \\
\quad \geq 850 \mathrm{ml}\end{array}$ & $281(57.1)$ & $75^{\mathrm{a}}$ & $68(60.7)$ & $110(55.6)$ & $65(59.1)$ & $38(52.8)$ & $286(57.3)$ & $75^{\mathrm{a}}$ & $86(55.8)$ & $132(57.4)$ & $68(59.1)$ \\
\hline Waist-Hip Ratio & $0.84(0.78-0.89)$ & 2 & $0.84(0.78-0.90)$ & $0.83(0.78-0.88)$ & $0.84(0.79-0.89)$ & $0.83(0.78-0.89)$ & $0.84(0.78-0.89)$ & 2 & $0.83(0.78-0.90)$ & $0.83(0.78-0.88)$ & $0.84(0.79-0.89)$ \\
\hline $\begin{array}{c}\text { Age at } \\
\text { menarche, yrs }\end{array}$ & $13(12-14)$ & 3 & $13(12-14)$ & $13(12-14)$ & $14(13-14)$ & $13(12-14)$ & $13(12-14)$ & 3 & $13(12-14)$ & $13(12-14)$ & $14(13-14)$ \\
\hline Parous & $485(85.5)$ & - & $111(85.4)$ & $192(86.9)$ & $108(82.4)$ & $74(87.1)$ & $490(85.4)$ & - & $156(86.2)$ & $222(86.4)$ & $112(82.4)$ \\
\hline Alcohol use & & 1 & & & & & & 1 & & & \\
\hline Never & $62(11.0)$ & & 19 (14.6) & $23(10.4)$ & $15(11.5)$ & $5(6.0)$ & $62(10.8)$ & & $23(12.8)$ & $24(9.3)$ & $15(11.0)$ \\
\hline $\begin{array}{l}\text { Not more than } \\
\text { once a month }\end{array}$ & $149(26.3)$ & & $37(28.5)$ & $57(25.8)$ & $34(26.0)$ & $21(25.0)$ & $154(26.9)$ & & $48(26.7)$ & 69 (26.8) & $37(27.2)$ \\
\hline $\begin{array}{l}\text { 2-4 times per } \\
\text { month }\end{array}$ & $216(38.2)$ & & $41(31.5)$ & $84(38.0)$ & $54(41.2)$ & $37(44.0)$ & 217 (37.9) & & $64(35.6)$ & $97(37.7)$ & $56(41.2)$ \\
\hline $\begin{array}{l}\text { 2-3 times per } \\
\text { week }\end{array}$ & $110(19.4)$ & & 27 (20.8) & $51(23.1)$ & $19(14.5)$ & $13(15.5)$ & $111(19.4)$ & & 34 (18.9) & $58(22.6)$ & $19(14.0)$ \\
\hline $\begin{array}{l}4 \text { or more times } \\
\text { per week }\end{array}$ & $29(5.1)$ & & $6(4.6)$ & $6(2.7)$ & $9(6.9)$ & $8(9.5)$ & $29(5.1)$ & & $11(6.1)$ & $9(3.5)$ & $9(6.6)$ \\
\hline $\begin{array}{l}\text { Pre-operative } \\
\text { smoker }\end{array}$ & $121(21.3)$ & - & $22(16.9)$ & $48(21.7)$ & $30(22.9)$ & $21(24.7)$ & $121(21.1)$ & - & $33(18.2)$ & $57(22.2)$ & 31 (22.8) \\
\hline $\begin{array}{c}\text { Smoker at any } \\
\text { visit }\end{array}$ & $129(22.8)$ & - & $23(17.7)$ & $51(23.1)$ & $32(24.4)$ & $23(27.1)$ & $130(22.6)$ & - & 36 (19.9) & $60(23.3)$ & $34(25.0)$ \\
\hline
\end{tabular}


Table 1 Patients included in the survival analyses stratified according to IL6 diplotype (A) and rs1800795 (B) (Continued)

\begin{tabular}{|c|c|c|c|c|c|c|c|c|c|c|c|}
\hline $\begin{array}{l}\text { Pre-operative } \\
\text { use of } \\
\text { antidepressants }\end{array}$ & $56(9.9)$ & - & $14(10.8)$ & $21(9.5)$ & $16(12.2)$ & $5(5.9)$ & $57(9.9)$ & - & $18(9.9)$ & $23(8.9)$ & $16(11.8)$ \\
\hline $\begin{array}{c}\text { Ever use of } \\
\text { HRT, \% }\end{array}$ & $263(46.5)$ & 1 & $54(41.9)$ & $102(46.2)$ & $70(53.4)$ & $37(43.5)$ & $267(46.6)$ & 1 & 77 (42.8) & $118(45.9)$ & $72(52.9)$ \\
\hline $\begin{array}{c}\text { Screening } \\
\text { detected tumor }\end{array}$ & $289(60.3)$ & $88^{b}$ & $59(56.7)$ & $102(54.8)$ & $78(68.4)$ & $50(66.7)$ & $293(60.5)$ & $90^{\mathrm{b}}$ & $84(56.8)$ & 129 (59.2) & $80(67.8)$ \\
\hline
\end{tabular}

*9 patients lacked genotype information.

**2 patients lacked genotype information.

***IQR Interquartile range.

${ }^{a}$ Analysis included women who had not gone through breast surgery before diagnosis.

${ }^{\mathrm{b}}$ Analysis included women $45-74$ years at diagnosis due to previous Swedish screening protocols. 
Table 2 Tumour characteristics for all patients included in the survival analyses, and stratified according to IL6 diplotype (A) and rs1800795 (B) (number of patients who had not received preoperative treatment indicated in boldface)

\begin{tabular}{|c|c|c|c|c|c|c|c|c|c|c|c|}
\hline & \multicolumn{6}{|c|}{ (A) } & \multicolumn{5}{|c|}{ (B) } \\
\hline & \multirow{2}{*}{\multicolumn{2}{|c|}{$\begin{array}{l}\text { Patients included } \\
\text { in the diplotype } \\
\text { survival analyses }\end{array}$}} & \multicolumn{4}{|c|}{ Stratified according to IL6 diplotype* } & \multirow{2}{*}{$\begin{array}{l}\text { Patients included } \\
\text { in the rs } 1800795 \\
\text { survival analyses }\end{array}$} & \multicolumn{4}{|c|}{ Stratified accoding to rs $1800795^{* *}$} \\
\hline & & & GGGC/GGGC & AGCC/GGGC & AGCC/AGCC & Rare diplotypes & & & GG & GC & CC \\
\hline & $\begin{array}{l}\text { Median }\left(\mathrm{IQR}^{* * *}\right) \\
\text { or } n(\%)\end{array}$ & Missing & $\begin{array}{l}\text { Median (IQR) } \\
\text { or } n(\%)\end{array}$ & $\begin{array}{l}\text { Median (IQR) } \\
\text { or } n(\%)\end{array}$ & $\begin{array}{l}\text { Median (IQR) } \\
\text { or } n(\%)\end{array}$ & $\begin{array}{l}\text { Median (IQR) } \\
\text { or } n(\%)\end{array}$ & $\begin{array}{l}\text { Median }\left(\mathrm{IQR}{ }^{* * *}\right) \\
\text { or } \mathrm{n}(\%)\end{array}$ & Missing & $\begin{array}{l}\text { Median (IQR) } \\
\quad \text { or } n(\%)\end{array}$ & $\begin{array}{l}\text { Median (IQR) } \\
\quad \text { or } n(\%)\end{array}$ & $\begin{array}{l}\text { Median (IQR) } \\
\text { or } n(\%)\end{array}$ \\
\hline & 567 & & $130(22.9)$ & $221(39.0)$ & $131(23.1)$ & $85(15.0)$ & 574 & & $181(31.5)$ & $257(44.8)$ & $136(23.7)$ \\
\hline $\begin{array}{l}\text { Preoperative interstitial } \\
\text { laser thermotherapy }\end{array}$ & $10(1.7)$ & & $3(2.1)$ & $4(1.7)$ & $2(1.5)$ & $1(1.1)$ & $10(1.6)$ & & $4(2.1)$ & $4(1.5)$ & $2(1.4)$ \\
\hline $\begin{array}{c}\text { Information on } \\
\text { preoperative treatment } \\
\text { missing }\end{array}$ & 1 & & 0 & 0 & 0 & 1 & 1 & & 0 & 1 & 0 \\
\hline Neoadjuvant therapy & $26(4.3)$ & & $8(5.7)$ & $9(3.9)$ & $5(3.6)$ & $4(4.4)$ & $26(4.3)$ & & $9(4.6)$ & $12(4.4)$ & $5(3.5)$ \\
\hline $\begin{array}{l}\text { No preoperative } \\
\text { treatment }\end{array}$ & 567 & & $130(22.9)$ & $221(39.0)$ & $131(23.1)$ & $85(15.0)$ & 574 & & $181(31.5)$ & $257(44.8)$ & $136(23.7)$ \\
\hline Invasive tumour size (pT) & & - & & & & & & - & & & \\
\hline$\geq 21 \mathrm{~mm}(\geq 2)$ & $150(26.5)$ & & $28(21.5)$ & $69(31.2)$ & $30(22.9)$ & $23(27.1)$ & $151(26.3)$ & & $40(22.1)$ & $80(31.1)$ & $31(22.8)$ \\
\hline In Situ & - & & - & - & - & - & - & & - & - & - \\
\hline$\leq 20 \mathrm{~mm}$ (1) & $417(73.5)$ & & $102(78.5)$ & $152(68.8)$ & $101(77.1)$ & $62(72.9)$ & $423(73.7)$ & & $141(77.9)$ & $177(68.9)$ & $105(77.2)$ \\
\hline $21-50 \mathrm{~mm}(2)$ & $141(24.9)$ & & $27(20.8)$ & $64(29.0)$ & 27 (20.6) & $23(27.1)$ & $142(24.7)$ & & 39 (21.5) & $75(29.2)$ & 28 (20.6) \\
\hline $51-\mathrm{mm}(3)$ & $8(1.4)$ & & $1(0.8)$ & $4(1.8)$ & $3(2.3)$ & 0 & $8(1.4)$ & & $1(0.6)$ & $4(1.6)$ & $3(2.2)$ \\
\hline $\begin{array}{l}\text { skin or muscle involvement } \\
\text { (4) }\end{array}$ & $1(0.2)$ & & 0 & $1(0.5)$ & 0 & 0 & $1(0.2)$ & & 0 & $1(0.4)$ & 0 \\
\hline $\begin{array}{l}\text { Axillary node } \\
\text { involvement }\end{array}$ & & 2 & & & & & & 2 & & & \\
\hline $\begin{array}{l}\text { Any lymph node } \\
\text { involvement }\end{array}$ & $217(38.4)$ & & $41(31.8)$ & $89(40.3)$ & $50(38.5)$ & $37(43.5)$ & $221(38.6)$ & & $62(34.4)$ & $108(42.0)$ & $51(37.8)$ \\
\hline 0 & $348(61.6)$ & & $88(68.2)$ & $132(59.7)$ & $80(61.5)$ & $48(56.5)$ & $351(61.4)$ & & $118(65.6)$ & $149(58.0)$ & $84(62.2)$ \\
\hline $1-3$ & $163(28.8)$ & & $29(22.5)$ & $70(31.7)$ & $36(27.7)$ & $28(32.9)$ & $167(29.2)$ & & $46(25.6)$ & $84(32.7)$ & $37(27.4)$ \\
\hline $4+$ & $54(9.6)$ & & $12(9.3)$ & $19(8.6)$ & $14(10.8)$ & $9(10.6)$ & $54(9.4)$ & & $16(8.9)$ & $24(9.3)$ & $14(10.4)$ \\
\hline Histological grade & & 1 & & & & & & 1 & & & \\
\hline Grade III & $111(19.6)$ & & $30(23.1)$ & $49(22.3)$ & $18(13.7)$ & $14(16.5)$ & $113(19.7)$ & & $37(20.4)$ & $57(22.3)$ & $19(14.0)$ \\
\hline I & $154(27.4)$ & & $29(22.3)$ & $64(29.1)$ & $40(30.5)$ & $22(25.9)$ & $157(27.4)$ & & $43(23.8)$ & $72(28.1)$ & $42(30.9)$ \\
\hline$\|$ & $298(53.0)$ & & $71(54.6)$ & $107(48.6)$ & $73(55.7)$ & $49(57.6)$ & $303(52.9)$ & & $101(55.8)$ & $127(49.6)$ & $75(55.1)$ \\
\hline III & 111 (19.6) & & $30(23.1)$ & 49 (22.3) & 18 (13.7) & $14(16.5)$ & $113(19.7)$ & & 37 (20.4) & $57(22.3)$ & 19 (14.0) \\
\hline
\end{tabular}


Table 2 Tumour characteristics for all patients included in the survival analyses, and stratified according to IL6 diplotype (A) and rs1800795 (B) (number of patients who had not received preoperative treatment indicated in boldface) (Continued)

\begin{tabular}{|c|c|c|c|c|c|c|c|c|c|c|c|}
\hline \multicolumn{12}{|c|}{ Hormone receptor status } \\
\hline ER+ & $492(87.1)$ & 2 & $106(81.5)$ & $192(86.9)$ & $118(90.8)$ & $76(90.5)$ & $499(87.2)$ & 2 & $152(84.4)$ & $224(87.2)$ & $123(91.1)$ \\
\hline PgR+ & $394(69.7)$ & 2 & $81(62.3)$ & $151(68.3)$ & $98(75.4)$ & $64(76.2)$ & $399(69.8)$ & 2 & $119(66.1)$ & 179 (69.6) & $101(74.8)$ \\
\hline $\mathrm{ER}+\mathrm{PgR}+$ & $390(69.0)$ & 2 & $80(61.5)$ & $149(67.4)$ & $97(74.6)$ & $64(76.2)$ & $395(69.1)$ & 2 & $118(65.6)$ & $177(68.9)$ & $100(74.1)$ \\
\hline ER+PgR- & $102(18.1)$ & 2 & $26(20.0)$ & $43(19.5)$ & $21(16.2)$ & $12(14.3)$ & $104(18.2)$ & 2 & $34(18.9)$ & $47(18.3)$ & $23(17.0)$ \\
\hline ER-PgR- & $69(12.2)$ & 2 & $23(17.7)$ & $27(12.2)$ & $11(8.5)$ & $8(9.5)$ & $69(12.1)$ & 2 & $27(15.0)$ & $31(12.1)$ & $11(8.1)$ \\
\hline ER-PgR+ & $4(0.7)$ & 2 & $1(0.8)$ & $2(0.9)$ & $1(0.8)$ & 0 & $4(0.7)$ & 2 & $1(0.6)$ & $2(0.8)$ & $1(0.7)$ \\
\hline
\end{tabular}

*9 patients lacked genotype information.

**2 patients lacked genotype information.

***IQR Interquartile range. 




Figure 1 Flow chart of the patient selection process.

chemotherapy, patients with the AGCC/AGCC diplotype had an increased risk of early events compared to patients with the GGGC/GGGC diplotype (adjusted $\mathrm{HR}=17.28$; 95\% CI 1.51-198.51; $P=0.022$ ). The addition of body constitution to the model did not essentially change the results, except for the case of the dichotomous variable WHR $>85$, which weakened the association (adjusted $\mathrm{HR}=9.00$; 95\% CI 0.71-114.02; $P=0.090$ ).

Radiotherapy-treated patients with ER-negative tumours who had either an AGCC/GGGC or an AGCC/AGCC diplotype had an increased risk of early events ( $\log$ Rank 3 df; $P=0.041$ ). No such association was observed for radiotherapy-treated patients with ER-positive tumours (Log Rank 3 df; $P=0.58$ ). In a multivariable model of patients with ER-negative tumours who had received radiotherapy, the association between the AGCC/AGCC diplotype and the risk of early events was borderline significant (adjusted $\mathrm{HR}=5.71 ; 95 \%$ CI
0.98-33.33; $P=0.053)$. Similar results were obtained when body constitution was added to the model.

Among patients who had not received chemotherapy and patients who had not received radiotherapy, IL6 diplotype was not associated with early events in any univariable or multivariable models.

\section{Early events in relation to the four individual IL6 SNPs}

To investigate whether any of the SNPs were driving the results, each SNP was examined. No association was observed between rs1800796 and rs2069849 and risk of early events when stratifying according to ER-status or breast cancer treatment (data not shown). However, both rs1800795 Any C-carriers and rs1800797 Any A-carriers had an increased risk of early events among various subgroups of patients. Since rs1800795 and rs1800797 had an $r^{2}=0.966$, we chose to continue our analyses with the most studied SNP: rs1800795. The following survival 




b Among patients with invasive ER-negative tumours

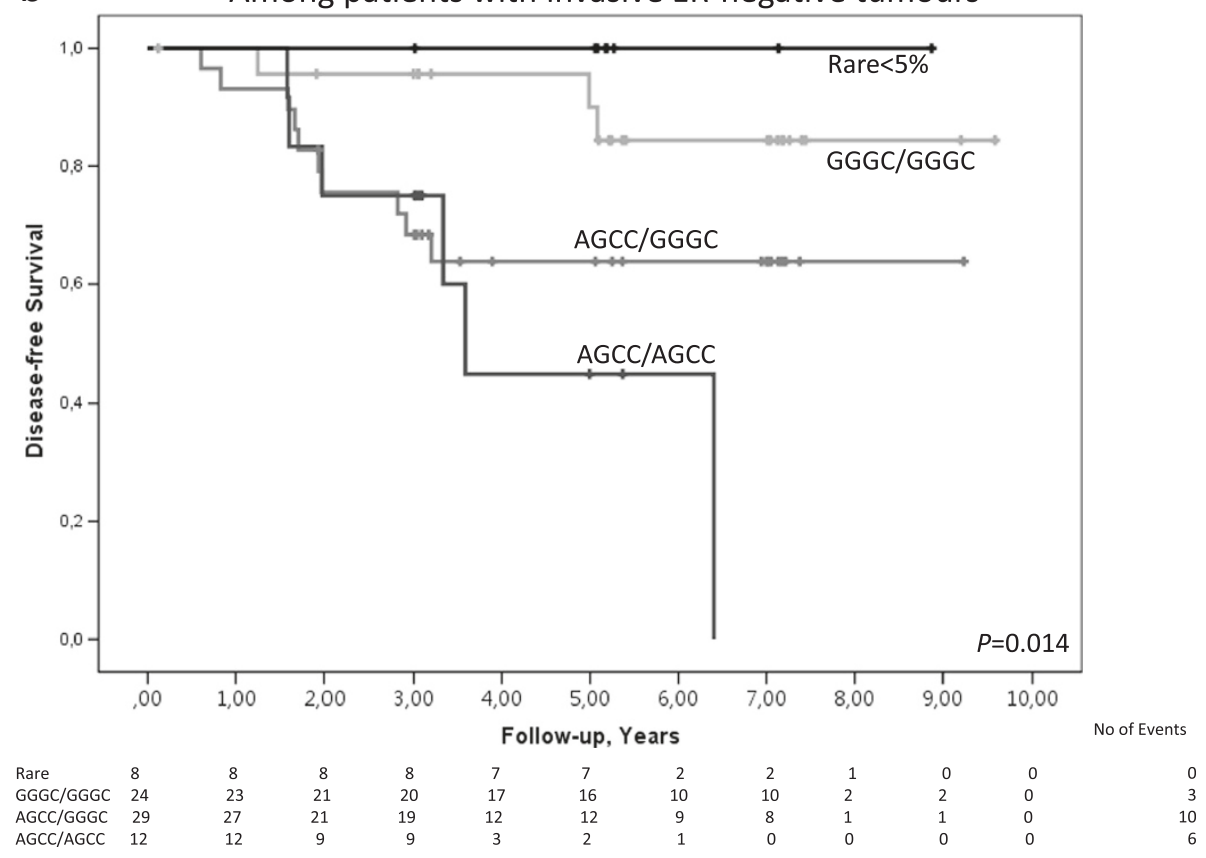

Figure 2 Breast cancer-free survival in relation to IL6 diplotype. Kaplan-Meier estimates of breast cancer-free survival in relation to IL6 diplotype. Since this is an ongoing cohort, there are fewer patients with longer follow-up times. a) Breast cancer-free survival among all patients with invasive tumours (Log Rank $3 \mathrm{df} ; P=0.83$ ). The adjusted HR was 1.14 (95\% Cl 0.62-2.10; $P=0.67)$. b) Breast cancer-free survival among patients with invasive ER-negative tumours (Log Rank $3 \mathrm{df} ; P=0.014)$. The adjusted HR was 5.91 (95\% Cl 1.28-27.42; $P=0.023$ ).

analyses were based on 574 patients as information on rs1800795 genotype was available for an additional seven patients with ER-positive tumours.

\section{Early events in relation to rs 1800795}

Among all patients, rs1800795 was not associated with early events in a univariable (Figure 3a; Log Rank 1 df; 


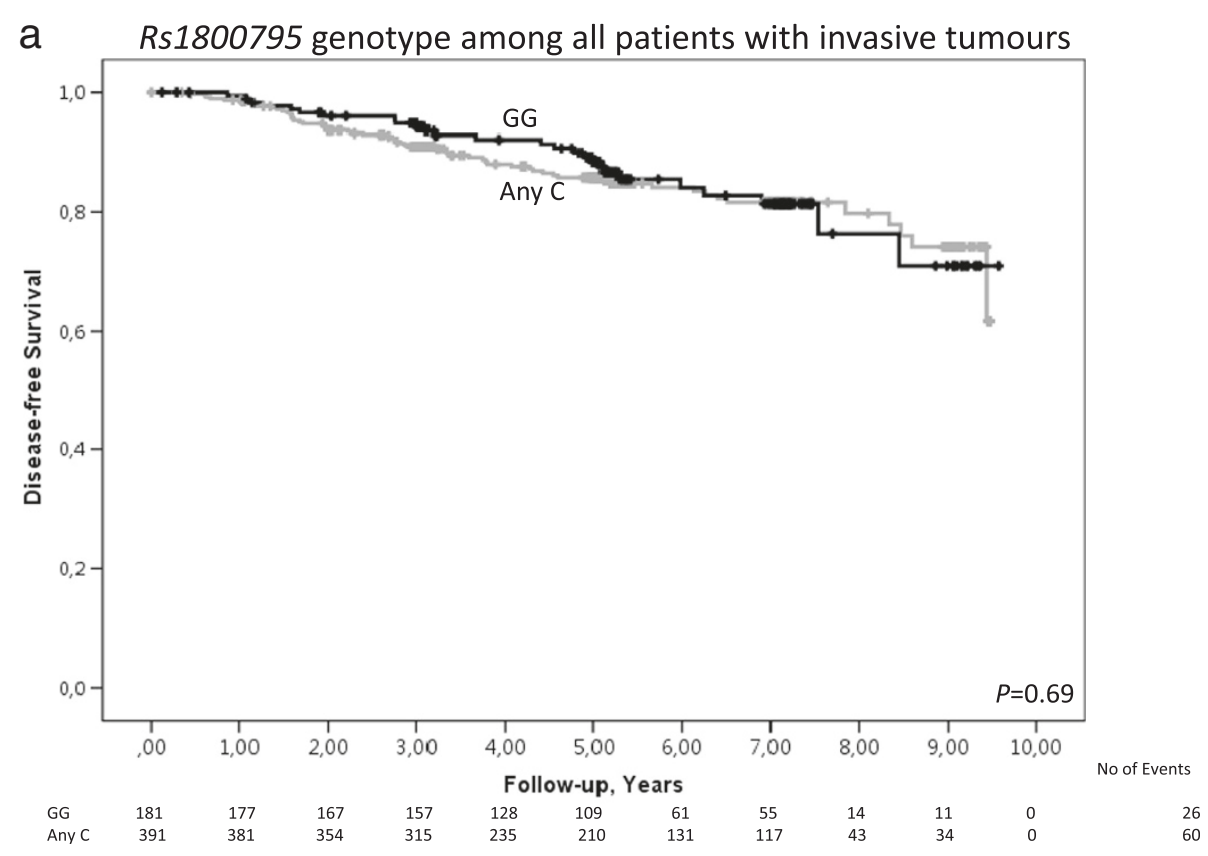

b Rs1800795 genotype among patients with invasive ER-negative tumours

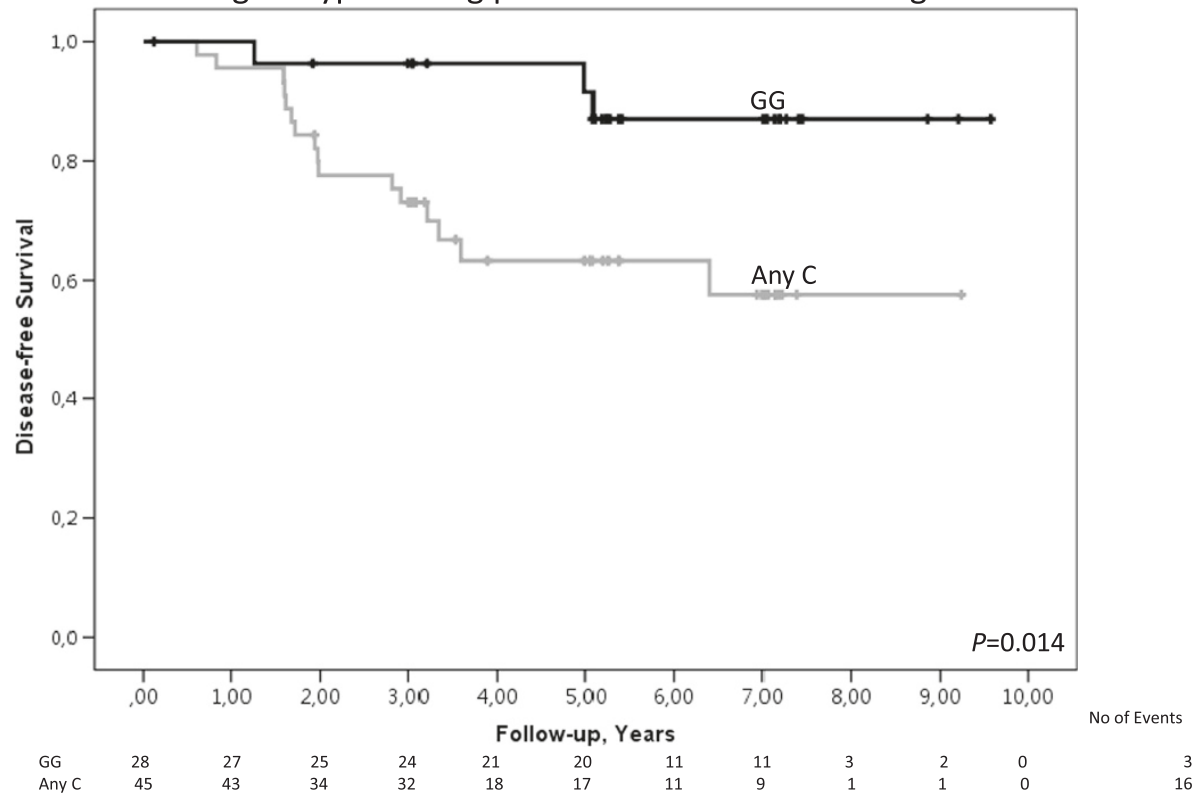

Figure 3 Breast cancer-free survival in relation to rs 1800795 genotype. Kaplan-Meier estimates of breast cancer-free survival in relation to rs1800795 genotype. Since this is an ongoing cohort, there are fewer patients with longer follow-up times. a) Breast cancer-free survival among all patients with invasive tumours (Log Rank $1 \mathrm{df} ; P=0.69$ ). The adjusted HR was 1.11 ( $95 \% \mathrm{Cl} 0.69-1.77 ; P=0.67)$. b) Breast cancer-free survival among patients with invasive ER-negative tumours (Log Rank $1 \mathrm{df} ; P=0.014$ ). The adjusted HR was 3.76 (95\% Cl 1.05-13.43; $P=0.041$ ).

$P=0.69$ ) or multivariable model (adjusted $\mathrm{HR}=1.11$; 95\% CI 0.69-1.77; $P=0.67)$. Adjusting for ER-status or body constitution generated similar results.

\section{Early events in relation to rs1800795 and ER-status}

Among patients with ER-negative tumours, Any Ccarriers had an increased risk of early events compared to GG-carriers (Figure 3b; Log Rank 1 df; $P=0.014$ ). This difference was also observed using a multivariable model (adjusted HR = 3.76; 95\% CI 1.05-13.43; $P=0.041$ ). The results were essentially the same when body constitution was added to the model.

Among patients with ER-positive tumours, rs1800795 was not associated with early events in a univariable 
model (Log Rank 1 df; $P=0.38$ ) or in a multivariable model (adjusted $\mathrm{HR}=0.79 ; 95 \% \mathrm{CI}$ 0.47-1.33; $P=0.37$ ). The addition of body constitution to the model yielded similar results.

\section{Early events in relation to rs1800795, ER-status, and breast cancer treatment}

Irrespective of ER-status, chemotherapy-treated Any Ccarriers had an increased risk of early events compared to GG-carriers (Figure 4a; Log Rank 1 df; $P=0.030$ ). This difference was also observed using a multivariable model (adjusted HR = 3.42; 95\% CI 1.01-11.54; $P=0.048$ ). When the dichotomous variable breast volume $\geq 850 \mathrm{ml}$ was added to the model, the association between being an Any C-carrier and having an increased risk of early events was strengthened (adjusted HR $=3.71$; 95\% CI 1.08-12.75; $P=0.037)$. The addition of ER-status or other body constitution-related parameters to the model did not essentially change the results.

Radiotherapy-treated Any C-carriers with ER-negative tumours had an increased risk of early events compared to GG-carriers (Figure 4b; Log Rank 3 df; $P<0.0001$ ). This finding was also observed using a multivariable model (adjusted HR = 7.17; 95\% CI 1.16-32.28; $P=0.010$ ). Similar results were obtained when body constitution was added to the model. No such association was observed among radiotherapy-treated Any C-carriers with ER-positive tumours.

Among patients who had not received chemotherapy and patients who had not received radiotherapy, rs1800795 was not associated with early events in any univariable or multivariable models.

\section{Early events in relation to rs1800795 and antidepressant treatment}

At the preoperative visit, 56 of the patients included in the survival analyses were undergoing some type of prescribed antidepressant treatment. Three of these patients ceased treatment during the first year after their breast cancer diagnosis. During the first year after diagnosis, 23 additional patients started antidepressant treatment. Any C-carriers $(n=383)$ were more likely to have started than to have ceased antidepressant treatment during the first year after their breast cancer diagnosis (McNemar's test $P=0.001)$. For $\mathrm{GG}$-carriers $(\mathrm{n}=176)$, this association was not significant (McNemar's test $P=0.11$ ); however, no significant differences were observed between Any C-carriers and GG-carriers.

No association was observed between antidepressant treatment prior to any breast cancer event and risk of early events, either at the preoperative visit (Log Rank 1 df; $P=0.61$ ) or during any visit up to the 1 -year visit (Log Rank 1 df; $P=0.32$ ). Multivariable models yielded similar results.

\section{Discussion}

The present study investigated the impact of IL6 genotype on early events and treatment response in an ongoing cohort of breast cancer patients. The main finding was that IL6 genotype was strongly associated with early events among patients with ER-negative tumours, especially in radiotherapy-treated patients, and among chemotherapytreated patients irrespective of ER-status. To our knowledge, the association of IL6 genotype with disease-free survival and treatment response in relation to tumour ER-status has not been previously investigated in a large population-based cohort of breast cancer patients.

The high-risk AGCC/AGCC diplotype contains the highrisk genotypes of the SNPs rs1800795 and rs1800797. The association between risk of early events and diplotype appears to be primarily driven by the SNPs rs1800795 and rs1800797, as no association was observed between the SNPs rs1800796 and rs2069849 and disease-free survival. Therefore, the discussion will focus primarily on the association between rs1800795 and disease-free survival.

Some studies reported that the rs1800795 C-allele was associated with reduced systemic levels of IL-6 [16,17]. However, several studies found that the lower levels of IL-6 that were observed among C-allele carriers compared to G-allele carriers were increased and surpassed the levels observed in G-allele carriers when both genotypes were subjected to inflammatory stimuli [14,33,34]. Therefore, we hypothesise that the C-allele is associated with increased levels of IL-6; however, this association only exists in the presence of inflammatory stimuli, such as ER-negativity, radiotherapy or chemotherapy. A tentative explanation for the association between IL6 genotype and inflammatory stimuli might be found in a differential reduction in the methylation of the IL6 promoter, because rs1800795 has been reported to be in linkage with the rs2069845 CpG site [35].

In the present study, IL6 genotype predicted diseasefree survival only among patients with ER-negative tumours, unless the patients had received chemotherapy. A previous study demonstrated that IL-6 constitutively activates the NF- $\kappa \beta$ pathway, which subsequently drives further IL-6 production, creating a positive feedback loop [36]. As reviewed by Shostack et al., NF-k $\beta$ plays a crucial role in breast cancer progression by stimulating proliferation and preventing apoptosis. NF- $k \beta$ is more frequently constitutively activated in ER-negative tumours than in ER-positive tumours, and ER $\alpha$ has been shown to repress NF- $\kappa \beta$ activation [37]. Further, NF- $\kappa \beta$ inhibition has been shown to inhibit proliferation of ER-negative cells [38]. If Any C-carriers with ER-negative tumours have an increased level of IL-6, an associated increase in NF-k $\beta$ may explain the impaired prognosis among those patients.

Among patients who had received chemotherapy, Any C-carriers had an over 3-fold increased risk of events 

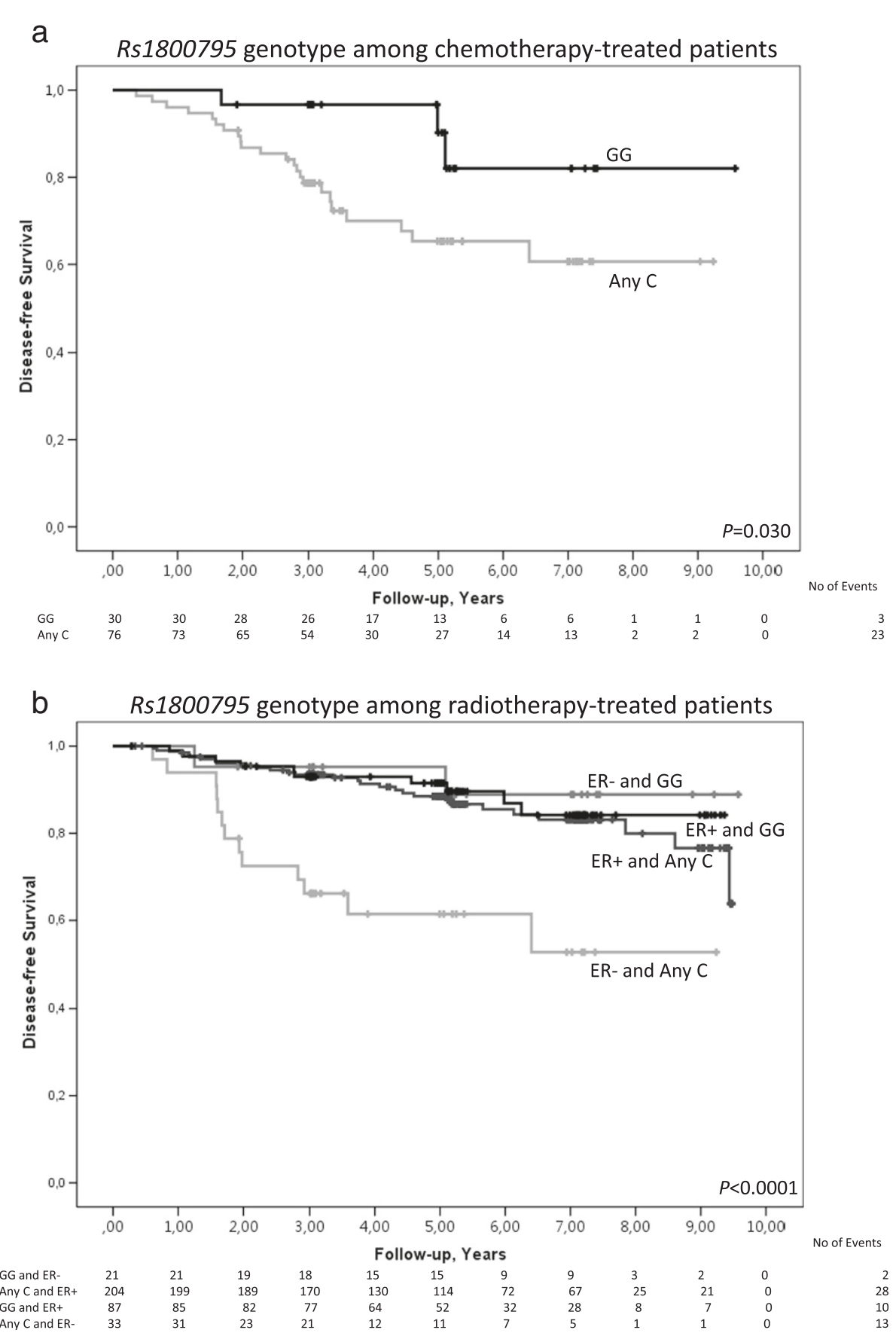

Figure 4 Breast cancer-free survival in different treatment groups in relation to rs1800795 genotype. a) Kaplan-Meier estimates of breast cancer-free survival in relation to rs1800795 genotype among chemotherapy-treated patients (Log Rank $1 \mathrm{df} ; P=0.030$ ). The adjusted HR was 3.42 (95\% Cl 1.01-11.54; $P=0.048$ ). Since this is an ongoing cohort, there are fewer patients with longer follow-up times. $\mathbf{b}$ ) Kaplan-Meier estimates of breast cancer-free survival in relation to rs 1800795 genotype among radiotherapy-treated patients (Log Rank 3 df; $P<0.0001$ ). The adjusted HR was $7.17(95 \% \mathrm{Cl} 1.16-32.28 ; P=0.010)$. Since this is an ongoing cohort, there are fewer patients with longer follow-up times.

compared to GG-carriers, regardless of their ER-status. Chemotherapy has been shown to increase IL-6 levels in breast cancer patients and to activate NF- $\kappa \beta[39,40]$. IL-6 levels and NF- $\kappa \beta$ activation are associated with chemotherapy resistance, and inhibition of NF- $\mathrm{k} \beta$ has sensitised chemotherapy resistant cell lines to chemotherapy $[6,41]$. The increased levels of IL-6 in Any C-carriers that occur in response to chemotherapy-associated inflammation and the related increase in NF- $\kappa \beta$ could explain the elevated risk of events among chemotherapy-treated Any 
C-carriers that was observed in the present study. Inhibitors of NF-k $\beta$ or IL- 6 could be of interest for this subgroup of patients.

In the present study, radiotherapy-treated Any C-carriers with ER-negative tumours had an over 7-fold increased risk of events compared to GG-carriers. IL- 6 levels and NF- $\kappa \beta$ activation have been linked to radiotherapy resistance [6]. In addition, in a randomised control trial, radiotherapy conferred significantly smaller improvements in recurrence control for patients with ER-negative tumours than for patients with ER-positive tumours [42]. A majority of the early events that occurred among Any C-carriers with ER-negative tumours were distant metastases ( 9 out of 13 events). Hence, the increased risk of this group cannot be explained by local radiotherapy resistance. Radiation induces inflammatory signalling, which lasts long beyond the initial radiation-induced burst [43]. This signalling is mainly executed via the activation of NF- $\kappa \beta$, but IL-6 levels have also been shown to increase [44]. According to our previously stated hypothesis, radiotherapy-induced inflammation would be particularly harmful for Any Ccarriers with ER-negative tumours, as this inflammation represents an additional inflammatory stimulus that induces Any C-carriers to release large amounts of systemic IL-6, explaining the impaired prognosis among those patients. Inhibitors of NF- $\alpha \beta$ or IL- 6 could be of interest for this subgroup of patients; previous studies reported promising results after treating radiotherapy resistance with NF- $\mathrm{k} \beta$ inhibitors [44].

The addition of body constitution to the multivariable models modified the association between IL6 genotype and disease-free survival in some subgroups. IL-6 levels and body constitution are closely linked. Body constitutionrelated parameters, such as obesity, a high WHR, and a large breast volume, are associated with breast cancer prognosis $[27,45,46]$. This association is believed to be mediated by chronic inflammation [47]. Our group recently reported that the inflammation-associated COX2 rs5277 SNP impacted breast cancer prognosis differently depending on tumour ER-status, type of breast cancer treatment, and body constitution [48]. However, no association was observed between rs5277 on chromosome 1 and rs1800795 on chromosome 7 (data not shown). Hence, the findings of the present study are independent from the previous study.

Although no association was observed between antidepressant use and genotype in the present study, the relationship between genotype and depression could not be assessed using our questionnaire. Depression is estimated to be underdiagnosed in cancer patients [49]. To properly investigate the association between genotype and depression, it would be necessary to collect additional information on depressive symptoms.

The results of the present study are in contrast to the results of two previous studies $[8,10]$, in which chemotherapy-treated GG-carriers with ER-positive tumours had a shorter disease-free survival than Any $\mathrm{C}$-carriers. However, these studies investigated this association in two smaller cohorts of chemotherapy-treated patients. One cohort had a median axillary lymph node involvement of 14 nodes, and in the other cohort, $81 \%$ of patients had $\geq 10$ positive lymph nodes. The present study and these previous studies are not comparable, because our cohort comprises a population-based series of breast cancer patients in which the majority of patients were node negative.

The present study did not have access to systemic IL-6 levels. However, intrapersonal IL-6 levels vary greatly depending on the time of day, food intake, recent exercise routines, et cetera [50]. Stable genomic information on inflammatory tendency may be superior for assessing ongoing systemic inflammation, as it is not affected by daily fluctuations. This study is population-based, and the included patients were similar to non-included patients with respect to age and hormone receptor status [22]. SNP genotyping is considered reliable in the present study, as over $10 \%$ of the samples were run in duplicate, with a concordance of $100 \%$. In the present study, the vast majority of patients were ethnic Swedes. Studies of the association between IL6 genotype and breast cancer prognosis in other ethnic groups are warranted.

Since the median follow-up time was only 5 years, the long-term effects of IL6 genotype on disease-free survival could not be evaluated. The estimated failure rates in the previous power calculation exceeded the observed failure rates; these failure rates may have influenced the power of this study. In addition, this study assessed a number of variables and some of the findings may be attributable to chance. The results must be confirmed in independent cohorts.

\section{Conclusions}

The main finding of the present study was that IL6 genotype was strongly associated with early events among patients with ER-negative tumours, particularly among radiotherapy-treated patients, and among chemotherapytreated patients irrespective of ER-status. We hypothesise that the mechanism that underlies this observation is that the rs1800795 C-allele is associated with increased systemic levels of IL- 6 in the presence of inflammatory stimuli, such as ER-negativity, radiotherapy, and chemotherapy. The high risk for early events observed in certain subgroups of patients suggests that combined information on IL6 genotype, tumour ER-status, and breast cancer treatment may represent a tool for identifying patients who require more personalised treatment, potentially using inhibitors of NF- $\mathrm{k} \beta$ or IL-6. 


\section{Additional files}

\section{Additional file 1: Patient characteristics for all patients, and for the} patients included in the survival analyses.

Additional file 2: Tumour characteristics for all patients, and for the patients included in the survival analyses.

\section{Abbreviations}

BMI: Body mass index; CRP: C-reactive protein; DNA: Deoxyribonucleic acid; ER: Oestrogen receptor; IL-6: Interleukin-6; IL6: Interleukin-6 gene;

IQR: Interquartile range; In: Natural logarithm; PgR: Progesterone receptor; SNP: Single nucleotide polymorphisms; WHR: Waist-to-hip ratio.

\section{Competing interests}

The authors declare that they have no competing interests.

\section{Authors' contributions}

AM has been involved in acquisition of data, analysis and interpretation of data, in drafting the manuscript, and have revised the manuscript critically for important intellectual content. MS has been involved in acquisition of data, analysis and interpretation of data, and in revising the manuscript critically for important intellectual content. Cl and CR have been involved in conception and design of the study, analysis and interpretation of data, and have revised the manuscript critically for important intellectual content. $\mathrm{HJ}$ has been involved in acquisition of data, in conception and design of the study, analysis and interpretation of data, in drafting the manuscript, and has revised the manuscript critically for important intellectual content. All authors have read and approved the final version of the manuscript.

\section{Acknowledgements}

We wish to thank our research nurses: Anette Ahlin Gullers, Monika Meszaros, Maj-Britt Hedenblad, Karin Henriksson, Anette Möller, and Linda Ågren. We also wish to thank Erika Bågeman, Maria Henningson, and Maria Hjertberg for data entry.

\section{Grant support}

This work was supported by grants from The Swedish Cancer Society CAN 2011/497, the Swedish Research Council K2012-54X-22027-01-3 (PI H Jernström), the Medical Faculty at Lund University, the Mrs. Berta Kamprad Foundation, the Gunnar Nilsson Foundation, the Swedish Breast Cancer Group (BRO), the South Swedish Health Care Region (Region Skåne ALF), Konung Gustaf V:s Jubileumsfond, and the Lund Hospital Fund.

\section{Author details}

${ }^{1}$ Division of Oncology and Pathology, Department of Clinical Sciences, Lund, Lund University, Barngatan 2B, Lund SE-22185, Sweden. Division of Surgery, Department of Clinical Sciences, SE-22185 Lund, Lund University and Skåne University Hospital, Lund, Sweden. ${ }^{3}$ CREATE Health and Department of Immunotechnology, Lund University, Medicon Village, Building 406, Lund S-22381, Sweden.

Received: 19 June 2014 Accepted: 3 October 2014

Published: 11 October 2014

\section{References}

1. Youlden DR, Cramb SM, Dunn NA, Muller JM, Pyke CM, Baade PD: The descriptive epidemiology of female breast cancer: an international comparison of screening, incidence, survival and mortality. Cancer Epidemiol 2012, 36:237-248

2. Musgrove EA, Sutherland RL: Biological determinants of endocrine resistance in breast cancer. Nat Rev Cancer 2009, 9:631-643.

3. Knupfer $H$, Preiss R: Significance of interleukin-6 (IL-6) in breast cancer (review). Breast Cancer Res Treat 2007, 102:129-135.

4. Salgado R, Junius S, Benoy I, Van Dam P, Vermeulen P, Van Marck E, Huget P, Dirix LY: Circulating interleukin-6 predicts survival in patients with metastatic breast cancer. Int J Cancer 2003, 103:642-646.

5. Zhang GJ, Adachi I: Serum interleukin-6 levels correlate to tumour progression and prognosis in metastatic breast carcinoma. Anticancer Res 1999, 19:1427-1432.
6. Seruga B, Zhang $H$, Bernstein $L$, Tannock IF: Cytokines and their relationship to the symptoms and outcome of cancer. Nat Rev Cancer 2008, 8:887-899.

7. Purohit A, Reed MJ: Regulation of estrogen synthesis in postmenopausal women. Steroids 2002, 67:979-983.

8. DeMichele A, Gray R, Horn M, Chen J, Aplenc R, Vaughan WP, Tallman MS: Host genetic variants in the interleukin-6 promoter predict poor outcome in patients with estrogen receptor-positive, node-positive breast cancer. Cancer Res 2009, 69:4184-4191.

9. Slattery ML, Curtin K, Baumgartner R, Sweeney C, Byers T, Giuliano AR, Baumgartner KB, Wolff RR: IL6, aspirin, nonsteroidal anti-inflammatory drugs, and breast cancer risk in women living in the southwestern United States. Cancer Epidemiol Biomarkers Prev 2007, 16:747-755.

10. DeMichele A, Martin AM, Mick R, Gor P, Wray L, Klein-Cabral M, Athanasiadis G, Colligan T, Stadtmauer E, Weber B: Interleukin-6-174G-C polymorphism is associated with improved outcome in high-risk breast cancer. Cancer Res 2003, 63:8051-8056.

11. Bower JE, Ganz PA, Irwin MR, Castellon S, Arevalo J, Cole SW: Cytokine genetic variations and fatigue among patients with breast cancer. J Clin Oncol 2013, 31:1656-1661.

12. lacopetta B, Grieu F, Joseph D: The $-174 \mathrm{G} / \mathrm{C}$ gene polymorphism in interleukin- 6 is associated with an aggressive breast cancer phenotype. Br J Cancer 2004, 90:419-422.

13. Panoulas VF, Stavropoulos-Kalinoglou A, Metsios GS, Smith JP, Milionis HJ, Douglas KM, Nightingale P, Kitas GD: Association of interleukin-6 (IL-6)-174G/C gene polymorphism with cardiovascular disease in patients with rheumatoid arthritis: the role of obesity and smoking. Atherosclerosis 2009, 204:178-183.

14. Brull DJ, Montgomery HE, Sanders J, Dhamrait S, Luong L, Rumley A, Lowe GD, Humphries SE: Interleukin- 6 gene $-174 \mathrm{~g}>\mathrm{c}$ and $-572 \mathrm{~g}>\mathrm{c}$ promoter polymorphisms are strong predictors of plasma interleukin-6 levels after coronary artery bypass surgery. Arterioscler Thromb Vasc Biol 2001, 21:1458-1463.

15. Jones KG, Brull DJ, Brown LC, Sian M, Greenhalgh RM, Humphries SE, Powell JT: Interleukin-6 (IL-6) and the prognosis of abdominal aortic aneurysms. Circulation 2001, 103:2260-2265.

16. Huang M, Wang L, Ma H, Wang J, Xiang M: Lack of an association between interleukin-6-174G/C polymorphism and circulating interleukin-6 levels in normal population: a meta-analysis. DNA Cell Biol 2013, 32:654-664.

17. Cole SW, Arevalo JM, Takahashi R, Sloan EK, Lutgendorf SK, Sood AK, Sheridan JF, Seeman TE: Computational identification of gene-social environment interaction at the human IL6 locus. Proc Natl Acad Sci U S A 2010, 107:5681-5686.

18. Falagas ME, Zarkadoulia EA, loannidou EN, Peppas G, Christodoulou C, Rafailidis PI: The effect of psychosocial factors on breast cancer outcome: a systematic review. Breast cancer research : BCR 2007, 9:R44.

19. Lanquillon S, Krieg JC, Bening-Abu-Shach U, Vedder H: Cytokine production and treatment response in major depressive disorder. Neuropsychopharmacology 2000, 22:370-379.

20. Navari RM, Brenner MC, Wilson MN: Treatment of depressive symptoms in patients with early stage breast cancer undergoing adjuvant therapy. Breast Cancer Res Treat 2008, 112:197-201.

21. Illman J, Corringham R, Robinson D Jr, Davis HM, Rossi JF, Cella D, Trikha M: Are inflammatory cytokines the common link between cancer-associated cachexia and depression? J Support Oncol 2005, 3:37-50.

22. Lundin KB, Henningson M, Hietala M, Ingvar C, Rose $C$, Jernström $H$ : Androgen receptor genotypes predict response to endocrine treatment in breast cancer patients. Br J Cancer 2011, 105:1676-1683.

23. Simonsson M, Söderlind V, Henningson M, Hjertberg M, Rose C, Ingvar C, Jernström H: Coffee prevents early events in tamoxifen-treated breast cancer patients and modulates hormone receptor status. Cancer Causes Control 2013, 24:929-940.

24. Ringberg A, Bågeman E, Rose C, Ingvar C, Jernström H: Of cup and bra size: reply to a prospective study of breast size and premenopausal breast cancer incidence. Int J Cancer 2006, 119:2242-2243. author reply 2244.

25. WHO: Physical status: the use and interpretation of anthropometry. Report of a WHO Expert Committee. World Health Organ Tech Rep Ser 1995, 854:1-452

26. Saunders JB, Aasland OG, Babor TF, de la Fuente JR, Grant M: Development of the Alcohol Use Disorders Identification Test (AUDIT): WHO 
Collaborative Project on Early Detection of Persons with Harmful Alcohol Consumption-II. Addiction 1993, 88:791-804.

27. Markkula A, Bromee A, Henningson M, Hietala M, Ringberg A, Ingvar C, Rose C, Jernström H: Given breast cancer, does breast size matter? Data from a prospective breast cancer cohort. Cancer Causes Control 2012. 23:1307-1316

28. Markkula A, Hietala M, Henningson M, Ingvar C, Rose C, Jernström H: Clinical profiles predict early nonadherence to adjuvant endocrine treatment in a prospective breast cancer cohort. Cancer Prev Res (Phila) 2012, 5:735-745.

29. Jernström H, Bågeman E, Rose $C$, Jönsson PE, Ingvar C: CYP2C8 and CYP2C9 polymorphisms in relation to tumour characteristics and early breast cancer related events among 652 breast cancer patients. $\mathrm{Br}$ J Cancer 2009, 101:1817-1823.

30. Bågeman $\mathrm{E}$, Ingvar $\mathrm{C}$, Rose $\mathrm{C}$, Jernström $\mathrm{H}$ : Coffee consumption and CYP1A2*1 F genotype modify age at breast cancer diagnosis and estrogen receptor status. Cancer Epidemiol Biomarkers Prev 2008, 17:895-901.

31. PS: Power and Sample Size Calculation version 3.0. 2009, [http://biostat.mc.vanderbilt.edu/wiki/Main/PowerSampleSize]

32. McShane LM, Altman DG, Sauerbrei W, Taube SE, Gion M, Clark GM: REporting recommendations for tumour MARKer prognostic studies (REMARK). Br J Cancer 2005, 93:387-391.

33. Cole SW, Arevalo JM, Manu K, Telzer EH, Kiang L, Bower JE, Irwin MR, Fuligni AJ: Antagonistic pleiotropy at the human IL6 promoter confers genetic resilience to the pro-inflammatory effects of adverse social conditions in adolescence. Dev Psychol 2011, 47:1173-1180.

34. Basso F, Lowe GD, Rumley A, McMahon AD, Humphries SE: Interleukin-6-174G $>C$ polymorphism and risk of coronary heart disease in West of Scotland coronary prevention study (WOSCOPS). Arterioscler Thromb Vasc Biol 2002, 22:599-604.

35. Khankhanian $P$, Baranzini SE, Johnson BA, Madireddy L, Nickles D, Croen LA, Wu YW: Sequencing of the IL6 gene in a case-control study of cerebral palsy in children. BMC Med Genet 2013, 14:126.

36. Iliopoulos D, Hirsch HA, Struhl K: An epigenetic switch involving NF-kappaB, Lin28, Let-7 MicroRNA, and IL6 links inflammation to cell transformation. Cell 2009, 139:693-706.

37. Shostak K, Chariot A: NF-kappaB, stem cells and breast cancer: the links get stronger. Breast Cancer Res 2011, 13:214.

38. Oida K, Matsuda A, Jung K, Xia Y, Jang H, Amagai Y, Ahn G, Nishikawa S, Ishizaka S, Jensen-Jarolim E, Matsuda H, Tanaka A: Nuclear factor-kB plays a critical role in both intrinsic and acquired resistance against endocrine therapy in human breast cancer cells. Sci Rep 2014, 4:4057.

39. Smith AK, Conneely KN, Pace TW, Mister D, Felger JC, Kilaru V, Akel MJ, Vertino PM, Miller AH, Torres MA: Epigenetic changes associated with inflammation in breast cancer patients treated with chemotherapy. Brain Behav Immun 2014, 38:227-236.

40. Bharti AC, Aggarwal BB: Nuclear factor-kappa B and cancer: its role in prevention and therapy. Biochem Pharmacol 2002, 64:883-888.

41. Wang CY, Cusack JC Jr, Liu R, Baldwin AS Jr: Control of inducible chemoresistance: enhanced anti-tumour therapy through increased apoptosis by inhibition of NF-kappaB. Nat Med 1999, 5:412-417.

42. Kyndi M, Sorensen FB, Knudsen H, Overgaard M, Nielsen HM, Overgaard J: Estrogen receptor, progesterone receptor, HER-2, and response to postmastectomy radiotherapy in high-risk breast cancer: the Danish Breast Cancer Cooperative Group. J Clin Oncol 2008, 26:1419-1426.

43. Schaue D, McBride WH: Links between innate immunity and normal tissue radiobiology. Radiat Res 2010, 173:406-417.

44. Multhoff $\mathrm{G}$, Radons J: Radiation, inflammation, and immune responses in cancer. Frontiers in oncology 2012, 2:58.

45. Borgquist $S$, Hjertberg $M$, Henningson $M$, Ingvar $C$, Rose $C$, Jernström $H$ : Given breast cancer, is fat better than thin? Impact of the estrogen receptor beta gene polymorphisms. Breast Cancer Res Treat 2013, 137:849-862.

46. Kwan ML, John EM, Caan BJ, Lee VS, Bernstein L, Cheng I, Gomez SL, Henderson BE, Keegan TH, Kurian AW, Lu Y, Monroe KR, Roh JM, Shariff-Marco S, Sposto R, Vigen C, Wu AH: Obesity and mortality after breast cancer by race/ethnicity: The California Breast Cancer Survivorship Consortium. Am J Epidemiol 2014, 179:95-111.
47. Rose DP, Vona-Davis L: Biochemical and molecular mechanisms for the association between obesity, chronic Inflammation, and breast cancer. Biofactors (Oxford, England) 2014, 40:1-12.

48. Markkula A, Simonsson M, Rosendahl AH, Gaber A, Ingvar C, Rose C, Jernström H: Impact of COX2 genotype, ER-status, and body constitution on risk of early events in different treatment groups of breast cancer patients. Int J Cancer 2014, 135:1898-1910.

49. Fann JR, Thomas-Rich AM, Katon WJ, Cowley D, Pepping M, McGregor BA, Gralow J: Major depression after breast cancer: a review of epidemiology and treatment. Gen Hosp Psychiatry 2008, 30:112-126.

50. Zhou X, Fragala MS, McElhaney JE, Kuchel GA: Conceptual and methodological issues relevant to cytokine and inflammatory marker measurements in clinical research. Curr Opin Clin Nutr Metab Care 2010, 13:541-547.

doi:10.1186/1471-2407-14-759

Cite this article as: Markkula et al:: IL6 genotype, tumour ER-status, and treatment predicted disease-free survival in a prospective breast cancer cohort. BMC Cancer 2014 14:759.

\section{Submit your next manuscript to BioMed Central and take full advantage of:}

- Convenient online submission

- Thorough peer review

- No space constraints or color figure charges

- Immediate publication on acceptance

- Inclusion in PubMed, CAS, Scopus and Google Scholar

- Research which is freely available for redistribution 